\title{
Research
}

\section{The Trade-off Between Housing Density and Sprawl Area: Minimizing Impacts to Carabid Beetles (Coleoptera: Carabidae)}

\author{
$\underline{\text { Sara A. Gagné }}^{1}$ and Lenore Fahrig
}

\begin{abstract}
Increasing housing density has negative effects on native biodiversity. This implies that we should build at low density to conserve native species. However, for a given human population, low-density development must cover a large area, resulting in sprawl. A pertinent question is then, at what housing density are the impacts of a given human population on native biodiversity minimized? We addressed this question with carabid beetles in Ottawa and Gatineau, Canada. First, we collected beetles at 22 sites representing a range of housing densities. We then used these data to estimate beetle abundance and species richness in hypothetical development scenarios representing the housing density/sprawl area trade-off. Our results suggest that clustering development at a high housing density minimizes the impacts of a given human population on carabid beetles. If these results are general across all forest taxa, then planning that favors densification rather than sprawl would minimize urbanization effects on forest biodiversity.
\end{abstract}

Key Words: development scenario; forest fragmentation; forest taxa; ground beetle; housing density; residential development; urban sprawl

\section{INTRODUCTION}

Urbanization generally has negative effects on native biodiversity. An increase in housing density along the rural-urban gradient is accompanied by decreases in the abundance and species richness of native insects, amphibians, lizards, birds, and mammals (reviewed in McKinney 2002 and Hansen et al. 2005), with strong declines for native specialists. Blair (1999) reported the near complete loss of native bird and butterfly species present in a biological preserve in California as housing density increased. Similarly, along a rural-urban gradient in Argentina, native rodent species were only encountered in a natural reserve and parklands with very few buildings (Cavia et al. 2009). Frog and toad populations in Iowan wetlands have also been found to decline with increasing housing density (Pillsbury and Miller 2008).

The implicit conservation implication of these findings is that we should build at low density over the landscape. However, to accommodate a given human population, low-density development must cover a large area, resulting in sprawl and significant negative impacts to native plant and animal communities (Odell and Knight 2001, Maestas et al. 2003, Hansen et al. 2005). A pertinent question is then, at what housing density are the impacts of a given human population on native biodiversity minimized? For a given human population, it is unclear whether the impacts on native biodiversity are less where housing density is high and sprawl area is small or where housing density is low and sprawl area is large. This question was recently listed as one of the 100 questions that, if answered and acted upon, would have the greatest impact on the conservation of biological diversity worldwide (Sutherland et al. 2009).

We chose to evaluate the housing density/sprawl area trade-off using carabid beetles (Coleoptera: Carabidae). Carabid beetles were particularly appropriate candidates for our study because of their abundance and diversity and the ease with which they can be sampled. The family Carabidae is also well described taxonomically, and individuals can be easily identified to species. In addition, carabid beetles are important prey for many taxa, including salamanders (Andreone et al. 1999), lizards (Hódar et al. 1996), bats (Arlettaz et al. 1993), and birds (Holland et al. 2006). Finally, the response of 
carabid beetles to urbanization has been quantified. Native forest specialist carabid beetle abundance and species richness in forest fragments have been found to decline with increasing intensity of surrounding urbanization (Sadler et al. 2006, Elek and Lövei 2007, Gaublomme et al. 2008, Magura et al. 2008).

We estimated the impacts of a given human population on carabid beetle abundance and species richness in Ottawa, Ontario and Gatineau, Quebec, Canada. Our methodology can be described in two parts. First, we collected carabid beetles in sites of the same size representing a range of housing densities. We then used these empirical data to estimate the abundance and species richness of carabid beetles in four hypothetical development scenarios representing the trade-off between housing density and sprawl area. Development scenarios were hypothetical forested landscapes of the same size that accommodated a given human population at different housing densities, resulting in dispersed, semi-compact, and compact development patterns (an undeveloped scenario was also created for comparison). We identified the housing density that minimized the impacts of a given human population on carabid beetles by comparing abundance and species richness estimates among scenarios.

\section{METHODS}

\section{Beetle abundance data collection}

\section{Study area}

We sampled carabid beetle populations at 22 sites in and around Ottawa, Ontario and Gatineau, Quebec, Canada (Fig. 1). The study area encompassed approximately $4040 \mathrm{~km}^{2}$ on both sides of the Ottawa River. The northern half of the study area forms part of the Southern Laurentians ecoregion of Quebec and is underlain by the Canadian Shield, composed mainly of massive Precambrian granite and gneiss. Elevation is commonly 300-600 m above sea level. The St. Lawrence Lowlands ecoregion is south of the Ottawa River and is underlain by flat-lying Palaeozoic strata with elevations rarely more than $150 \mathrm{~m}$ above sea level. All housing categories (see below) were approximately equally represented in both ecoregions to account for possible differences in forest composition (Fig. 1). In addition, we tested a posteriori for differences in tree community composition between ecoregions using a redundancy analysis. The single constrained axis was not significant (100 permutations, $F_{1,2}=2.37, P=0.29$ ).

\section{Site selection}

We selected four sites in each of four housing density categories: Forested $\left(0\right.$ dwellings $\left./ \mathrm{km}^{2}\right)$, Exurban $\left(<56\right.$ dwellings $/ \mathrm{km}^{2}$, mean $=31 \pm 9$ [SE] dwellings $\left./ \mathrm{km}^{2}\right)$, Suburban (140-712 dwellings/ $\mathrm{km}^{2}$, mean $=555 \pm 101[\mathrm{SE}] \mathrm{dwellings} / \mathrm{km}^{2}$ ), and Urban (> 1244 dwellings $/ \mathrm{km}^{2}$, mean $=3754 \pm 492$ [SE] dwellings $/ \mathrm{km}^{2}$ ) (Fig. 2A). Housing density values for each category were derived from those used by previous authors (Kluza et al. 2000, Marzluff 2001, Odell and Knight 2001, Theobald 2001, Gillham 2002) and reflect the distribution of housing densities in the study area. Each site comprised the area within a $500 \times 500 \mathrm{~m}$ square $\left(0.25 \mathrm{~km}^{2}\right)$. Residential development in Exurban, Suburban, and Urban sites was dominated by traditional land covers, such as pavement and lawns and gardens surrounding homes. In Exurban sites, single-family homes and their associated gardens were separated by natural habitat (forest) within which recreation occurred (e.g., trail use). Suburban and Urban sites were composed exclusively of developed area, consisting of single-family homes and small parks with play structures in Suburban sites and a mix of single-family homes and multifamily complexes (e.g., low-rise and high-rise apartment buildings), small parks, and small shops in Urban sites. Thus, in our hypothetical development scenarios (see below), we compared residential developments composed of similar land covers and land uses (but different densities). In addition to these 16 sites, we selected six forested sites, equal in size to those described above, adjacent to developments of Suburban or Urban housing densities (three sites each) (Fig. 2B). In contrast to Forested sites, which were embedded in a larger forested area, these Neighbor sites were chosen to incorporate the possible effects of adjacent urban development on carabid beetle populations in forest habitat. Forested sites adjacent to undeveloped forest were represented by our Forested site category. We did not select any forested sites adjacent to Exurban-density development because the hypothetical landscapes we used to characterize the housing density/sprawl area gradient (see below) did not contain any forested areas adjacent to Exurban-density development. 
Fig. 1. The study area in and around the cities of Ottawa, Ontario and Gatineau, Quebec, Canada. Inset depicts the location of the study area in eastern Canada. Beetle survey sites are $0.25-\mathrm{km}^{2}$ areas indicated by symbols representing six housing categories: Forested (circles, 0 dwellings $/ \mathrm{km}^{2}$ ), Exurban (crosses, < 56 dwellings $/ \mathrm{km}^{2}$ ), Suburban (stars, 140-712 dwellings $/ \mathrm{km}^{2}$ ), Urban (asterisks, > 1,244 dwellings $/ \mathrm{km}^{2}$ ); and two categories of forested sites adjacent to developments of Suburban or Urban densities: Suburban Neighbor (squares) and Urban Neighbor (diamonds). Dark gray lines indicate roads. Forest cover is in green, large waterbodies are in blue, and urban land cover is in pink.

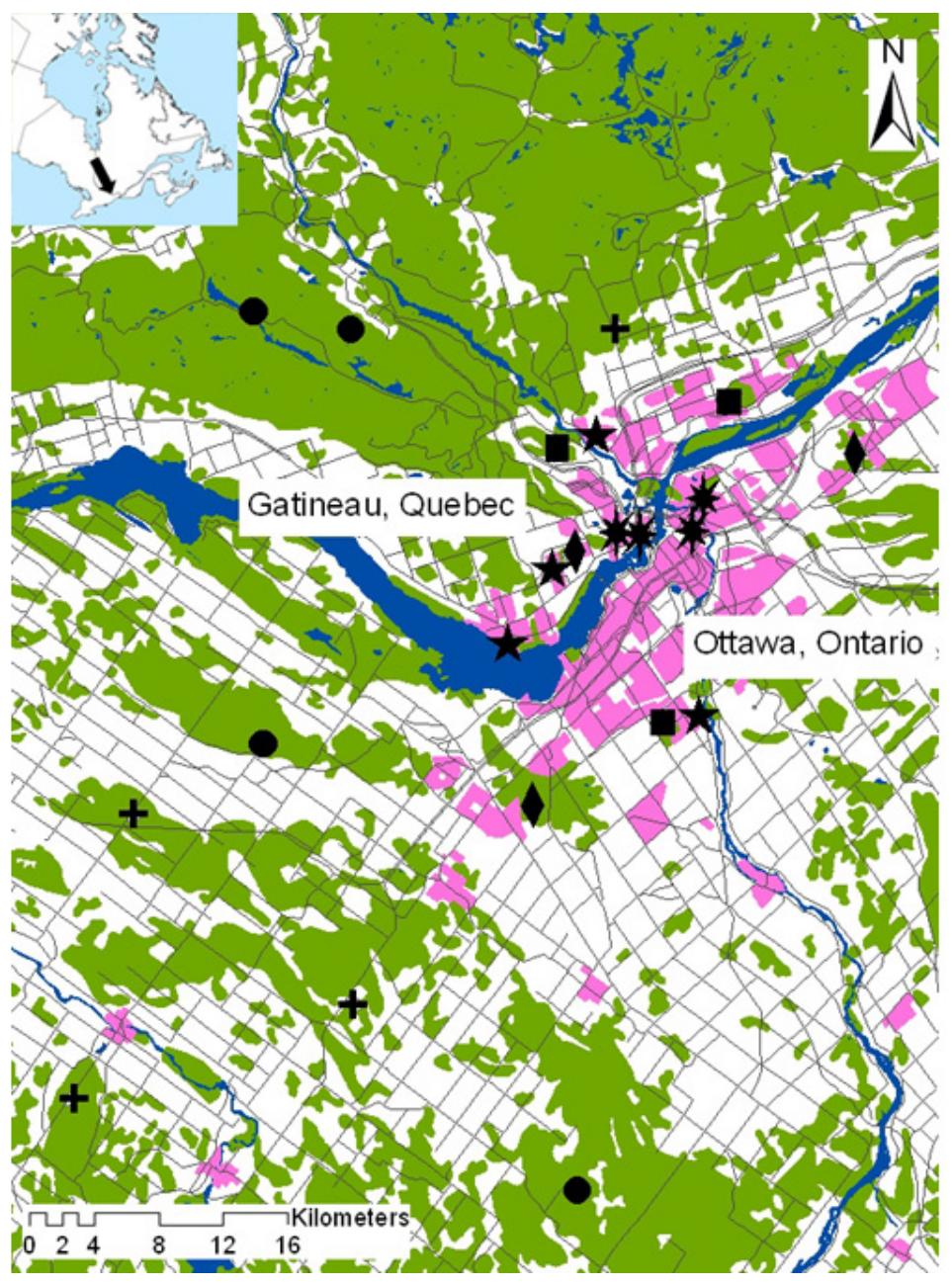

We searched for sites using a combination of historical topographic maps $(\sim 1 / 50,000$, currently produced by the Centre for Topographic Information, Natural Resources Canada, Ottawa, Ontario, Canada) and the most recent aerial photographs available (2002, 1/15,000, produced by the City of Ottawa, Ontario, Canada). Historical topographic maps were derived from aerial photography approximately every 10 years (depending on the area) and depicted detailed ground relief, drainage, forest cover, populated areas, transportation infrastructure, and individual human-made features (e.g., buildings, dams). Current maps depict wooded areas at least $250 \mathrm{~m}$ in diameter, populated areas (excluding parks, cemeteries, and open space at least $0.01 \mathrm{~km}^{2}$ in area) at least $0.25 \mathrm{~km}^{2}$ in area, and water bodies at least $50 \mathrm{~m}$ in diameter. Contour intervals are at least 10 
Fig. 2. Typical sites in which carabid beetles were surveyed. All beetle survey sites were $500 \times 500 \mathrm{~m}$. The planned locations of pitfall trapping stations are shown as yellow stars (see text for how planned and actual station locations differed). (A) Example sites representing a range of housing densities; we surveyed four replicate sites of each type. (B) Example Urban Neighbor site: the $500 \times 500 \mathrm{~m}$ forested beetle survey site was adjacent to at least $500 \times 500 \mathrm{~m}$ of Urban-density development. We surveyed three replicate Neighbor sites adjacent to each of the Suburban and Urban housing density levels.
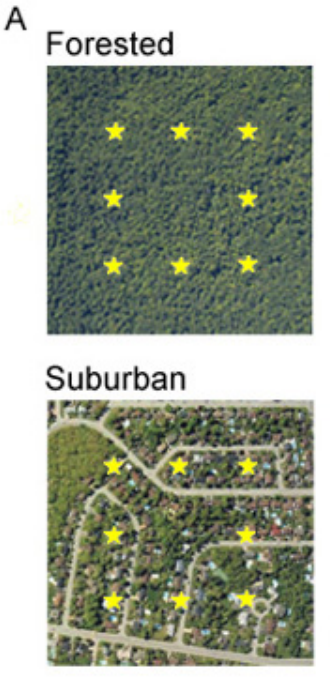
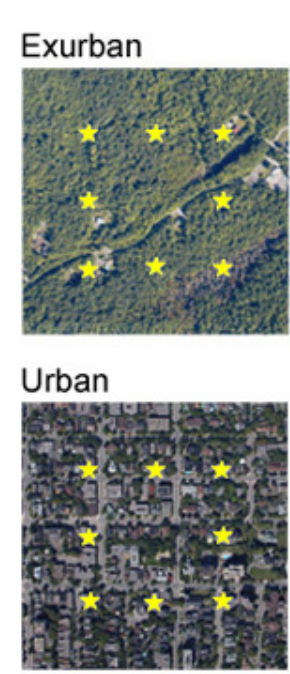

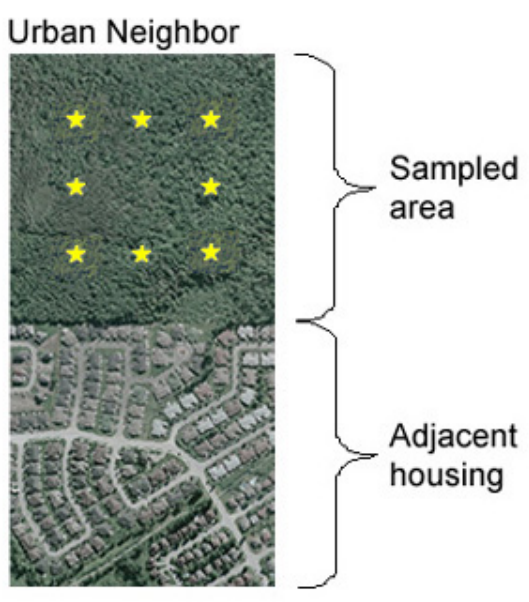

m. We located areas that were forested prior to development using historical topographic maps. We then checked the present housing density of these areas on aerial photographs to determine whether they could be placed into our predefined categories. In this way, we selected sites that were not subjected to agricultural use for at least as many years as topographic maps have been produced ( $\sim 80$ years). No other land use, with the exception of urbanization and recreation, occurred at our sites. We also attempted to standardize development age among sites. Unfortunately, urban sites that were forested prior to development were rare, forcing us to select two sites that were developed in the early 19 th century. The remainder of the sites were developed between 1922 and the present, with most development occurring in the $1960 \mathrm{~s}$. We minimized edge effects by choosing only sites that were surrounded by $>100 \mathrm{~m}$ of development of a similar housing density or forest cover, depending on the category. Due to the scarcity of sites satisfying the above criteria, we were unable to choose sites representing only one forest type. Instead, our sites represented a variety of mature forest types found in the area, such as Fagus grandifolia Ehrh.-Acer saccharum Marsh. and Thuja occidentalis L.-Abies balsamea L.-Picea mariana Mill. communities. However, all of our housing categories included a similar representation of forest types. In addition, we did not control for differences in microhabitat among our survey sites. We considered such differences to be the result of differences in housing density among sites, the ultimate driver of changes to beetle community structure in this study. Finally, the number of dwellings at each site and in $500 \times$ $500 \mathrm{~m}$ developed areas adjacent to Neighbor forest sites were counted on the ground in August 2006.

\section{Carabid beetle surveys}

We installed pitfall traps for carabid beetles at eight stations in each site in late April and early May 2007 , immediately following the spring thaw. The planned locations of traps conformed to a grid pattern at each site, with traps $125 \mathrm{~m}$ apart (Fig. 2). If a planned trap location occurred on a rooftop or other impervious surface, the actual trap was installed as close as possible to the planned location. 
In most instances, lack of landowner consent was the cause of discrepancies between planned and actual trap locations, resulting in some trap locations being moved $10-20 \mathrm{~m}$ ( $200 \mathrm{~m}$ in one case) from planned locations in Urban and Suburban sites, and 50-150 m from planned locations in Exurban sites. Traps consisted of two plastic cups, approximately $8 \mathrm{~cm}$ wide at the mouth and $10 \mathrm{~cm}$ tall. We buried traps in the ground with the rim of the inner cup flush with the ground surface. The base of the outer cup was punctured to allow for water drainage. We placed a $10 \times 10 \mathrm{~cm}$ plastic roof, supported by 2.54 $\mathrm{cm}$ nails at each corner, above each trap to prevent rain and debris from falling in the trap. We filled traps with $100 \mathrm{~mL}$ of propylene glycol and a drop of dish soap. We opened traps May 14 and replaced trap contents weekly until August 3. Thus, we collected beetles continuously over a 12-week period that encompassed the peak in carabid breeding activity in the region (Levesque and Levesque 1986). Carabid beetles were identified to species using Lindroth (1961-1969). Nomenclature followed Bousquet and Larochelle (1993).

The imperfect detectability of individuals during sampling has become a major topic of discussion among empiricists (Johnson 2008). Catches from pitfall traps represent not only carabid beetle abundance, but also the activity level of individuals, trap efficiency, and the sampling design. Detectability is maximized when pitfall trap catches represent the largest possible proportion of the true number of carabid beetles in the environment. We maximized detectability by (1) trapping beetles during the peak activity period of species in our region (see above), thus maximizing the likelihood that individuals would encounter a trap; (2) using a fluid in traps that has been recommended for use in pitfall trapping of carabid beetles due to its low evaporation rate and high preservation of specimens (Lemieux and Lindgren 1999, Isono 2005); (3) using dish soap in traps to prevent escape $(\mathrm{H}$. Goulet, Agriculture and Agri-Food Canada, personal communication); (4) using traps with a diameter large enough to capture large-bodied beetle individuals but small enough to minimize the catch of vertebrates (amphibians and small mammals) (Work et al. 2002); (5) installing traps with drainage holes and roofs to ensure their proper functioning throughout the season; (6) collecting trap contents weekly to minimize predation by necrophagous beetles (H. Goulet, personal communication); and (7) installing the maximum number of traps per site that we could feasibly operate considering our weekly collection schedule, site size $\left(0.25 \mathrm{~km}^{2}\right)$, and the driving distances between sites. In addition, we used the summed catch of individuals over the entire season as our estimate of the relative abundance of species at sites (see below) because this measure has previously been shown to be significantly positively correlated with true density $(r \geq 0.91)$ for two carabid beetle species (Baars 1979).

\section{Comparison of development scenarios}

\section{Hypothetical development scenarios}

We used the data described above to estimate carabid beetle abundance and species richness along a gradient of increasing housing density and decreasing sprawl area. We represented this gradient with hypothetical development scenarios (Fig. 3). Development scenarios can be envisioned as forested landscapes of the same size, into which the same number of dwellings were placed, but in contrasting patterns. One end of the gradient, where housing density is low and sprawl area is large, was represented by the Dispersed scenario, which was completely covered by Exurban-density development. The other end of the gradient, where housing density is high and sprawl area is small, was represented by the Compact scenario. The Compact scenario was home to the same number of dwellings as the Dispersed scenario, but the dwellings were clustered at an Urban density and the remainder of the Compact scenario was undeveloped forest. We also estimated carabid beetle abundance and species richness for an intermediate development scenario, the Semi-compact scenario. Here, the same number of dwellings as in the other two development scenarios was represented at a Suburban density, with the remainder of the Semi-compact scenario in undeveloped forest. Finally, for comparison, we estimated carabid beetle abundance and species richness for an Undeveloped scenario, that is, the same area as for the developed scenarios but covered entirely in forest.

We defined a development scenario as a $22.96 \mathrm{~km}^{2}$ square area, or an area equivalent to 91.83 units of the $500 \times 500 \mathrm{~m}\left(0.25 \mathrm{~km}^{2}\right)$ beetle survey sites. We arrived at this development scenario size by calculating the area required to accommodate a given number of dwellings (the mean number of dwellings at our Urban and Urban Neighbor beetle survey sites [712 dwellings]) at the lowest housing density (the Exurban density, mean $=31$ dwellings/ 
Fig. 3. Hypothetical development scenarios representing a gradient of increasing housing density and decreasing sprawl area. For a given forested area (the Undeveloped scenario), the same number of dwellings is depicted at three housing densities (Exurban, Suburban, and Urban), resulting in Dispersed, Semi-compact, and Compact development patterns, respectively. Yellow and brown areas represent forest habitat adjacent to development typical of Suburban Neighbor and Urban Neighbor sites, respectively. Drawings, including proportions of each cover type in each scenario, are not to scale. For example, the developed portion of the Semi-compact scenario was $6.18 \%$ of the total area of the scenario. Scenarios were $22.96 \mathrm{~km}^{2}$.

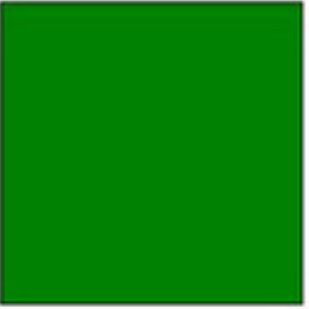

Undeveloped

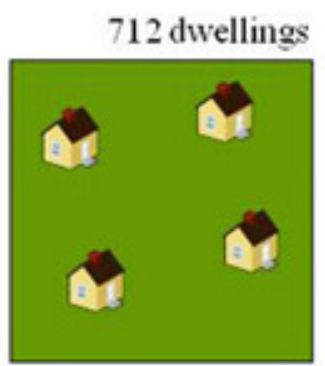

Dispersed

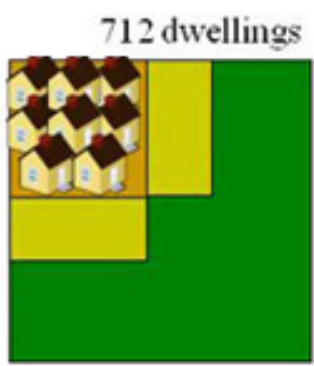

Semi-compact

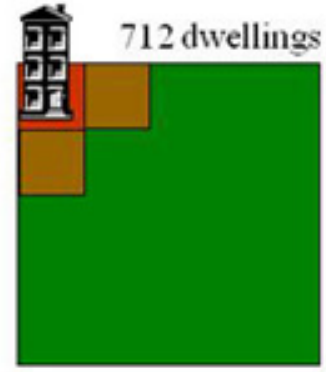

Compact

Housing density

Sprawl area

$\mathrm{km}^{2}$ ). In this way, we created our Dispersed scenario, covered entirely by 712 dwellings at the Exurban housing density or, equivalently, 91.83 Exurban beetle survey sites. In a similar fashion, we determined the size of the developed area (measured in $\mathrm{km}^{2}$ or in the number of Suburban or Urban beetle survey sites) within the Semi-compact and Compact scenarios. For these, we created square developed areas, positioned in one corner of each development scenario, to represent the area needed to contain 712 dwellings at the mean Urban or Suburban densities $\left(0.25 \mathrm{~km}^{2}\right.$ and $1.42 \mathrm{~km}^{2}$, respectively). For the Semicompact and Compact scenarios, we assumed that the forest cover adjacent to the developed area had carabid beetle abundances and species richnesses typical of our Neighbor beetle survey sites adjacent to Suburban- and Urban-density development, respectively. We calculated the area of this adjacent forest cover as the number of Neighbor beetle survey sites required to line both edges of the developed area. This pattern matches the spatial arrangement of our Neighbor beetle survey sites, which shared one complete edge with development (Fig. 2B). Finally, we assumed that the remaining area in the Semi-compact and Compact scenarios was typical of our Forested beetle survey sites. We assumed the Undeveloped scenario was covered entirely in forest cover typical of our Forested beetle survey sites.

\section{Theoretical carabid beetle species abundances}

For each development scenario, we estimated the abundance of each carabid beetle species collected during our surveys. First, we calculated the relative abundance of a species at each beetle survey site by summing the numbers of individuals of the species collected at all eight stations in the site over the entire survey period (Appendix 1). Recall that we measured the area of each development scenario in terms of the numbers of beetle survey sites of each housing category making up the development 
scenario (see above). Therefore, to estimate the total abundance of a species for a development scenario, we moved through the scenario, one site area at a time, and randomly selected a relative abundance for the species from one of the three or four beetle survey sites in that housing category (Fig. 4). For areas in the development scenario making up proportions of beetle survey sites, we multiplied the randomly selected abundance value by that proportion. We summed these 91.83 relative abundance values to yield the estimated abundance of a species in the whole development scenario. For example, Fig. 4 depicts the estimation of the abundance of a beetle species in the Semi-compact scenario. The Semi-compact scenario is shown as the equivalent area of many beetle survey sites in three different housing categories: Suburban, Suburban Neighbor, and Forested. For each site area in the Semi-compact scenario, a relative abundance value for the beetle species was randomly selected from among those of the beetle survey sites in that housing category. For instance, the developed portion of the Semi-compact scenario has been "filled in" with randomly selected relative abundance values of the beetle species from the four Suburban beetle survey sites. The randomly selected abundance values for the entire Semicompact scenario were then summed to yield an estimate of the abundance of the beetle species over the whole area of the Semi-compact scenario. We repeated this estimation procedure 1000 times for each species, resulting in an abundance distribution for each species in each development scenario. In the same manner, we also estimated the total abundance of all carabid beetles in each development scenario and the abundance of beetles belonging to species classified as forest, openhabitat, native, and non-native in each development scenario (Appendix 2).

\section{Theoretical carabid beetle species richnesses}

We estimated the species richness of all carabid beetles, forest beetles, and open-habitat beetles in each development scenario. Using species accumulation curves constructed for each housing category and for each beetle group (Colwell and Coddington 1994), we estimated that we collected $>89 \%$ of species predicted to be present in each type of site. Therefore, we assumed that we recorded the entire community of beetles present in each housing category. Using this information, we estimated the species richness of each beetle group in each development scenario with a procedure similar to that described for abundance. For each site area in a development scenario, we randomly selected an actual sampled site from the appropriate housing category and applied the species observed there to the site area in the development scenario. We repeated this procedure for every site area in the development scenario, successively adding any new species to the development scenario's species list. For areas in the development scenario making up fractions of beetle survey site areas, we randomly selected without replacement the observations from two, four, or six of the trapping stations within the beetle survey site, depending on the size of the fraction. The development scenario's final species list once every site area had been "filled" with species was the species richness of that whole development scenario.

Initially, the total number of beetle survey sites available for selection differed among development scenarios (four each in the Undeveloped and Dispersed scenarios and 11 each in the Semicompact and Compact scenarios). For example, recall that the Dispersed scenario was considered as the equivalent area to 91.83 Exurban beetle survey sites. However, there were only four Exurban beetle survey sites from which species observations could be used to estimate species richness in the Dispersed scenario. The Compact scenario, on the other hand, was made up of areas represented by beetle survey sites in three housing categories: Urban, Urban Neighbor, and Forested. Thus, observations from 11 beetle survey sites (four Urban, three Urban Neighbor, and four Forested) could be used to estimate species richness in the Compact scenario. This represented a difference in sample size among the development scenarios, which could bias the results such that the estimated richnesses in the Undeveloped and Dispersed scenarios would be lower than they should be, relative to the richnesses of the Semi-compact and Compact scenarios. We corrected for this by randomly selecting two Forested beetle survey sites, one Suburban or Urban site, and one Suburban Neighbor or Urban Neighbor site prior to estimating the species richness of each beetle group in the Semi-compact and Compact scenarios. For example, for the Semi-compact scenario, we randomly selected two Forested sites, one Suburban site, and one Suburban Neighbor site. These four beetle survey sites represented the pool from which species observations could be selected according to the procedure described above. Thus, for the Semi-compact and Compact scenarios, the 
Fig. 4. Illustration of the method for estimating the abundance of a carabid beetle species in a development scenario. Shown is the Semi-compact scenario (see Fig. 3; not to scale). Numbers represent the relative abundance of the species in each beetle survey site, calculated from pitfall trap data. Three types of beetle survey sites make up the Semi-compact scenario: Suburban, Suburban Neighbor, and Forested. For each site area in the scenario, a relative abundance value was randomly chosen from those of the replicate beetle survey sites in the appropriate housing category. To illustrate this, the developed portion of the scenario has been filled in with randomly chosen relative abundance values from the Suburban beetle survey sites. For areas in the development scenario that were smaller than site areas, the relative abundance value was multiplied by the proportion of a site area represented. Finally, the randomly selected values for the entire Semi-compact scenario were summed to yield an estimate of the abundance of the carabid beetle species in the whole development scenario.

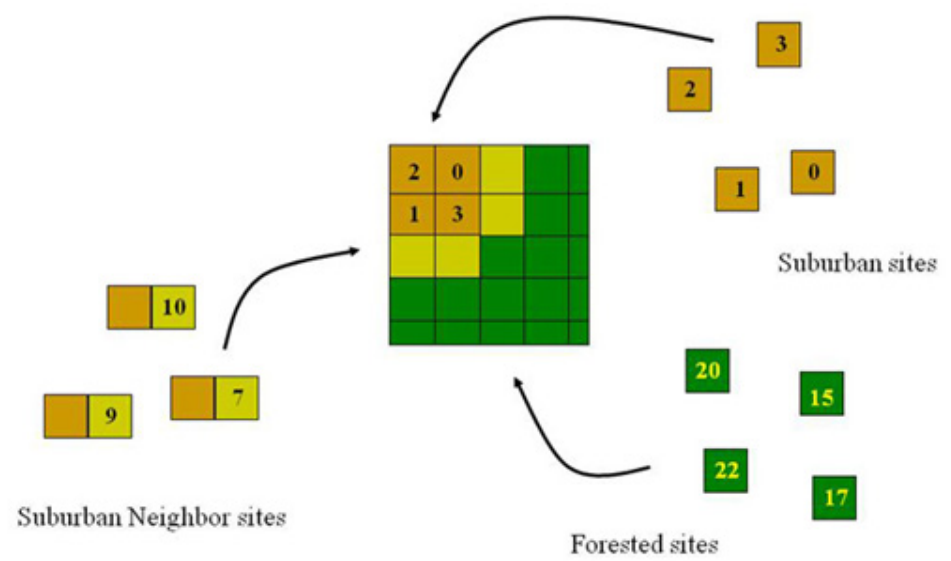

initial number of beetle survey sites available for selection was restricted to four to equal the number of beetle survey sites available for the Undeveloped and Dispersed scenarios. Finally, we repeated the entire species richness estimation procedure 1000 times to yield an estimate of the species richness of each beetle group and its associated error in each development scenario. All analyses were carried out using R version 2.6.2 (R Development Core Team 2008).

\section{RESULTS AND DISCUSSION}

We collected 4630 individuals from 90 species during our surveys (Appendix 1). We classified 26 species as forest species, 41 species as open-habitat species, 80 species as native species, and 10 species as non-native species (Appendix 2). We collected 694 individuals of the most abundant species, Pterostichus mutus, which occurred at 13 of the 22 survey sites (Appendix 1). The most widespread species, Carabus nemoralis, $P$. melanarius, and $P$. pensylvanicus, occurred at 17 survey sites each. We collected only one individual of 16 species during our surveys.

The abundances and species richnesses of forest beetles, open-habitat beetles, and non-native beetles were significantly affected by the housing density of survey sites (Table 1). Forest beetle abundance and species richness were significantly lower in Suburban and Urban survey sites than in sites in the other housing categories. Open-habitat beetles were significantly more abundant in Suburban compared with Forested survey sites, whereas the Suburban and Urban housing categories had significantly more open-habitat beetle species than the Forested or Suburban Neighbor categories. Forested survey sites had significantly fewer non-native beetles than sites in the other housing categories.

The estimates of carabid beetle abundance and species richness in hypothetical development scenarios suggest that clustering development at a Suburban or Urban housing density minimizes the 
Table 1. Carabid beetle abundance and species richness (mean \pm SE) at $500 \times 500 \mathrm{~m}$ beetle survey sites in six housing categories (see Methods for category definitions). The species included in each group are given in Appendix 2. Different lowercase letters indicate significant pairwise differences between categories for those response variables for which housing category had a significant effect in single-factor analyses of variance (square-root or log transformations were applied to response variables prior to analyses if the assumptions of normality and homoscedasticity were not met).

\begin{tabular}{|c|c|c|c|c|c|c|}
\hline & Forested & Exurban & Suburban & Urban & $\begin{array}{l}\text { Suburban } \\
\text { Neighbor }\end{array}$ & $\begin{array}{l}\text { Urban } \\
\text { Neighbor }\end{array}$ \\
\hline$n$ & 4 & 4 & 4 & 4 & 3 & 3 \\
\hline $\begin{array}{l}\text { Housing density } \\
\text { (mean dwellings } / \mathrm{km}^{2} \\
\pm \mathrm{SE})\end{array}$ & 0 & $31.00 \pm 9.30$ & $555.00 \pm 101.10$ & $\begin{array}{l}3754.00 \\
\pm 491.92\end{array}$ & $434.68 \pm 159.53$ & $1637.32 \pm 281.98$ \\
\hline \multicolumn{7}{|l|}{$\underline{\text { All beetles }}$} \\
\hline Abundance & $181.75 \pm 49.51$ & $151.50 \pm 28.01$ & $208.50 \pm 56.99$ & $136.25 \pm 38.72$ & $238.00 \pm 81.22$ & $428.67 \pm 114.57$ \\
\hline Species richness & $18.00 \pm 4.26$ & $25.00 \pm 2.80$ & $21.50 \pm 2.90$ & $18.75 \pm 2.72$ & $14.33 \pm 4.06$ & $23.00 \pm 3.46$ \\
\hline \multicolumn{7}{|l|}{$\underline{\text { Forest beetles }}$} \\
\hline Abundance & $117.00 \pm 30.82^{\mathrm{a}}$ & $73.25 \pm 14.42^{\mathrm{a}}$ & $6.75 \pm 1.93^{\mathrm{b}}$ & $3.50 \pm 1.32^{\mathrm{b}}$ & $54.00 \pm 22.81^{\mathrm{a}}$ & $97.33 \pm 8.65^{\mathrm{a}}$ \\
\hline Species richness & $9.50 \pm 0.87^{\mathrm{a}}$ & $9.25 \pm 0.75^{\mathrm{a}}$ & $2.00 \pm 0.41^{\mathrm{b}}$ & $1.50 \pm 0.29^{b}$ & $6.00 \pm 1.53^{\mathrm{a}}$ & $9.33 \pm 0.88^{\mathrm{a}}$ \\
\hline \multicolumn{7}{|l|}{ Open-habitat beetles } \\
\hline Abundance & $37.50 \pm 32.31^{\mathrm{a}}$ & $29.00 \pm 10.19^{\mathrm{ab}}$ & $131.25 \pm 49.49^{b}$ & $71.75 \pm 28.29^{\mathrm{ab}}$ & $38.33 \pm 17.70^{\mathrm{ab}}$ & $158.67 \pm 77.92^{\mathrm{ab}}$ \\
\hline Species richness & $2.25 \pm 0.95^{\mathrm{a}}$ & $6.75 \pm 2.59^{\mathrm{ab}}$ & $11.75 \pm 1.70^{\mathrm{b}}$ & $11.00 \pm 2.27^{b}$ & $2.33 \pm 0.88^{\mathrm{a}}$ & $3.00 \pm 1.00^{\mathrm{ab}}$ \\
\hline $\begin{array}{l}\text { Native beetle } \\
\text { abundance }\end{array}$ & $179.25 \pm 48.58$ & $121.50 \pm 25.50$ & $142.25 \pm 50.76$ & $76.75 \pm 29.10$ & $114.67 \pm 36.98$ & $321.33 \pm 70.55$ \\
\hline $\begin{array}{l}\text { Non-native beetle } \\
\text { abundance }\end{array}$ & $2.50 \pm 1.04^{\mathrm{a}}$ & $30.00 \pm 10.82^{\mathrm{b}}$ & $66.25 \pm 19.14^{\mathrm{b}}$ & $59.50 \pm 10.02^{\mathrm{b}}$ & $123.33 \pm 67.40^{\mathrm{b}}$ & $107.33 \pm 64.54^{\mathrm{b}}$ \\
\hline
\end{tabular}

impacts of a given human population on carabid beetle communities. In particular, we estimated that high-density development over a small area (the Compact scenario) resulted in the highest abundance and species richness of forest beetles when compared with other development patterns (Figs. 5B, 6B). We also estimated the abundance of native beetles and total beetle species richness to be highest in the Compact scenario (Figs. 5D, 6A). The Semi-compact scenario had the highest estimated total beetle abundance (Fig. 5A), likely due to openhabitat beetles having their highest estimated abundance in this scenario (Fig. 5C). Open-habitat beetles were also most speciose in the Semicompact scenario (Fig. 6C). The Dispersed scenario was characterized by the highest estimated abundance of non-native beetles (Fig. 5E).

Very little is presently known about how plants and animals respond to the housing density/sprawl area trade-off. We are aware of only three other studies that have compared plant or animal community structure between clustered or compact development and dispersed development (Kleppel et al. 2004, Lenth et al. 2006, Gagné and Fahrig in press). Kleppel et al. (2004) compared the biomasses of emergent vascular plants, phytoplankton, and zooplankton between wetlands situated in watersheds dominated by traditional small town 
Fig. 5. The estimated abundances of five carabid beetle groups in four hypothetical development scenarios: U, Undeveloped; D, Dispersed; SC, Semi-compact; C, Compact. (A) All beetles. (B) Forest beetles. (C) Open-habitat beetles. (D) Native beetles. (E) Non-native beetles. The species included in each group are given in Appendix 2. The lower edge of each box is the first quartile, the bold center line is the median, and the upper edge is the third quartile of the distribution. Whiskers extend to the minimum and maximum values.

A

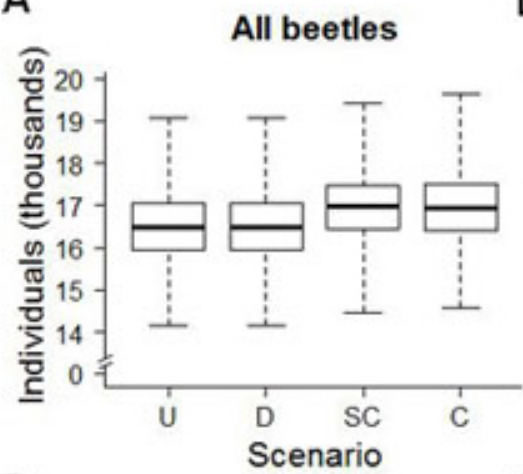

B
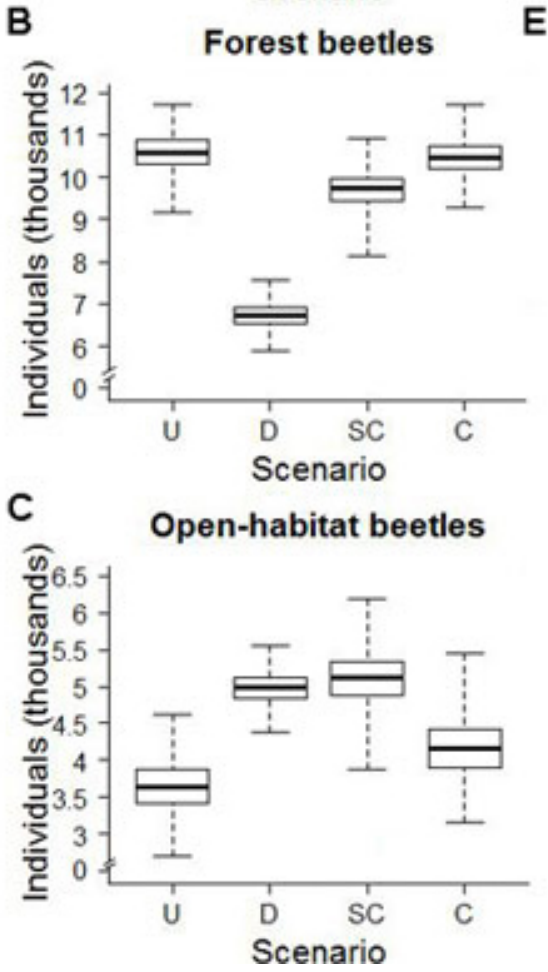

D

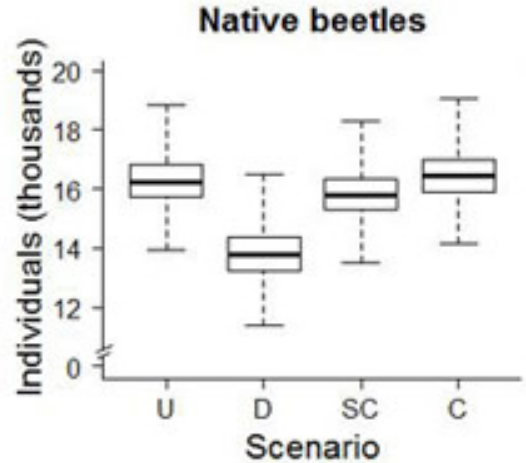

$E$

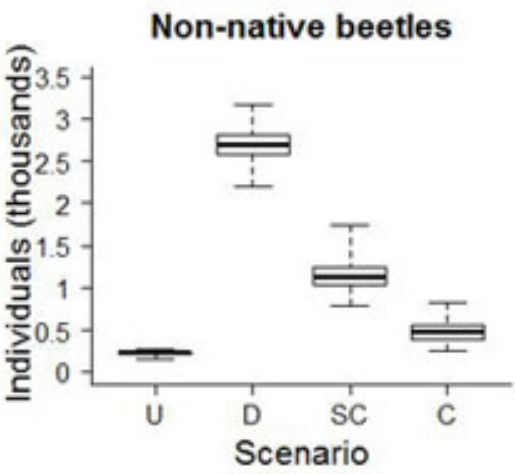


Fig. 6. The estimated species richnesses of three carabid beetle groups in four hypothetical development scenarios: U, Undeveloped; D, Dispersed; SC, Semi-compact; C, Compact. (A) All beetles. (B) Forest beetles. (C) Open-habitat beetles. The species included in each group are given in Appendix 2. The lower edge of each box is the first quartile, the bold center line is the median, and the upper edge is the third quartile of the distribution. Whiskers extend to the minimum and maximum values. Species richness estimates for the Undeveloped and Dispersed scenarios had zero variance. This is because every beetle species collected in the four Forested survey sites (for the Undeveloped scenario) and the four Exurban survey sites (for the Dispersed scenario) was always estimated to be in at least one of the large number (91.83) of replicate site areas in these scenarios.
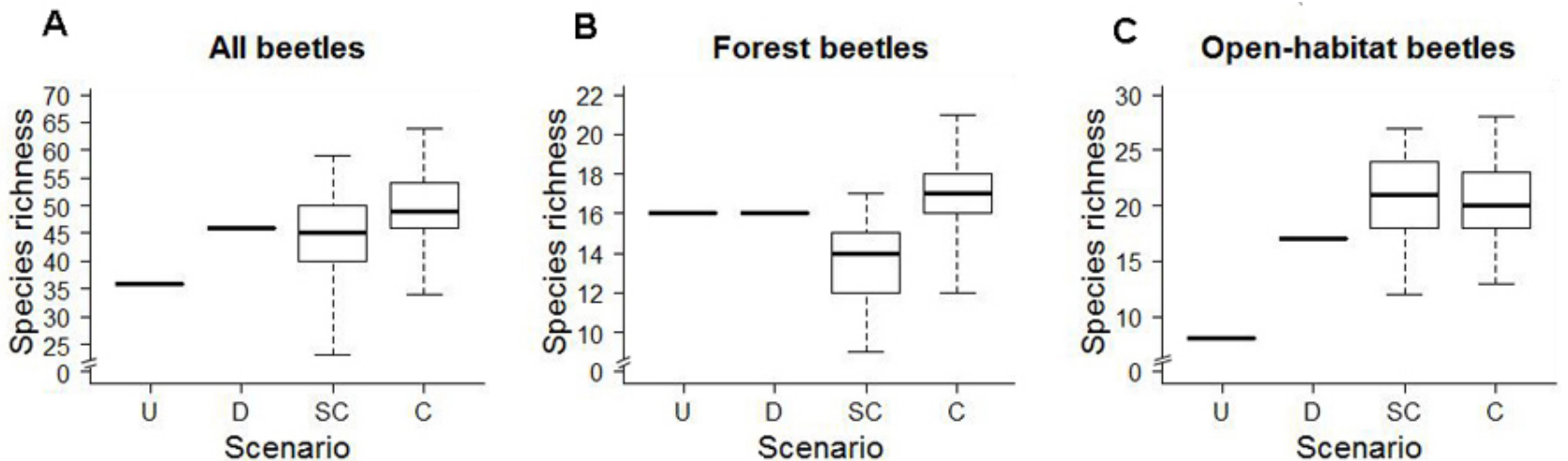

development (high housing density and small sprawl area) or suburban development (low housing density and large sprawl area) in the Hudson River Valley of New York State. Lenth et al. (2006) compared bird, mammal, and plant communities among clustered developments, dispersed developments, and undeveloped prairie in Colorado. Neither study found significant differences in algal or animal communities between development types, although Kleppel et al. (2004) did report increased dominance of the emergent plant community by invasive species and decreased trophic transfer function (the ratio of zooplankton biomass to phytoplankton biomass) in suburban wetlands. In a separate study (Gagné and Fahrig in press), we found that estimated forest breeding bird abundance and species richness in the same hypothetical scenarios showed similar trends to those reported here for forest carabid beetles: forest birds, and in particular forest interior birds, were most abundant in the Compact scenario and most speciose in the Semicompact scenario (not including the Undeveloped scenario). A synthesis of the results described in this paragraph is difficult because Kleppel et al. (2004) and Lenth et al. (2006) did not explicitly control for landscape size and number of dwellings, whereas Gagné and Fahrig (in press) and this study did so (recall that hypothetical development scenarios were $22.96 \mathrm{~km}^{2}$ and contained 712 dwellings). Thus, the results of Kleppel et al. (2004) and Lenth et al. (2006) are confounded by these variables, obscuring the trade-off between housing density and sprawl area.

We chose to estimate carabid beetle abundances and species richnesses in hypothetical development scenarios of a particular size, yet choice of spatial scale could be expected to change these estimates. Scenario size and structure were determined according to two observed values: the mean number of dwellings in the Urban and Urban Neighbor housing categories and the mean housing density of Exurban survey sites. Variation in these values would change scenario size, as well as the areas covered by development and Neighboring forest cover in the Semi-compact and Compact scenarios. Thus, whereas the Undeveloped and Dispersed scenarios would be covered entirely in forest cover or Exurban-density development regardless of spatial scale, the proportions of the Semi-compact 
and Compact scenarios covered by development and neighboring forest cover would change with spatial scale. To illustrate this, we calculated scenario size and the areas covered by Urbandensity development and Urban Neighbor forest cover in the Compact scenario for differing numbers of dwellings and housing density values. To accommodate the maximum number of dwellings in Urban and Urban Neighbor survey sites (1167 dwellings) at the minimum Exurban housing density (12 dwellings $/ \mathrm{km}^{2}$ ), scenario size would have to be $97.25 \mathrm{~km}^{2}$. Urban survey site areas would cover $0.26 \%$, Urban Neighbor survey site areas would cover $0.51 \%$, and Forested survey site areas would cover $99.23 \%$ of the Compact scenario. Conversely, if one wished to accommodate the minimum number of dwellings in Urban and Urban Neighbor survey sites (311 dwellings) at the maximum Exurban housing density (56 dwellings $/ \mathrm{km}^{2}$ ), scenario size would shrink to $5.55 \mathrm{~km}^{2}$, of which $4.50 \%$ would be covered by Urban survey site areas, $9.00 \%$ would be covered by Urban Neighbor survey site areas, and $86.50 \%$ would be covered by Forested survey site areas for the Compact scenario. These calculations exemplify that the Compact scenario will remain largely composed of Forested survey site areas despite an order of magnitude change in spatial scale (recall that the proportions of Urban, Urban Neighbor, and Forested survey site areas for the scenario size used in this paper [22.96 $\mathrm{km}^{2}$ ] were $1.09 \%, 2.18 \%$, and $96.73 \%$, respectively, in the Compact scenario). The results we report here mainly stem from the Semi-compact and Compact scenarios being largely made up of Forested survey site areas compared with the Dispersed scenario being covered entirely in Exurban-density development. Thus, these results are not likely to change significantly with a change in spatial scale of the magnitude described above. However, the use of numbers of dwellings and housing densities outside of the ranges observed in our survey sites may result in significant changes in the proportions of cover types in the Semi-compact and Compact scenarios, possibly engendering departures from the carabid beetle estimates we calculated here.

The results of Gagné and Fahrig (in press) and those presented here indicate that taxa that have previously been found to exhibit strong declines in response to increasing housing density (forest breeding birds [Friesen et al. 1995] and forest carabid beetles [Magura et al. 2008]) have their highest estimated abundances and species richnesses in compact rather than dispersed development (due to the former being surrounded by a large area of forest cover). Future research on the effects of the housing density/sprawl area tradeoff on forest biodiversity should focus on evaluating the responses of taxa other than carabid beetles and breeding birds to determine whether all forest taxa that are negatively affected by increasing housing density reach higher abundances and species richnesses in compact rather than dispersed development. If this is the case, then the conservation implications for forest biodiversity of building compact rather than dispersed development in rapidly urbanizing regions would be significant.

Such work would necessitate the sampling of animal populations at spatial scales matching those at which taxa perceive and interact with the environment. Large-bodied taxa perceive and interact with the environment at larger spatial scales than small-bodied taxa (Holling 1992). Thus, to determine the effect of the housing density/sprawl area trade-off on a large-bodied taxon using the method described in this paper, populations of the taxon would be sampled in survey sites larger than those used here for carabid beetles $\left(0.25 \mathrm{~km}^{2}\right)$. Ideally, a preliminary investigation of the survey site size at which a taxon most strongly responds to housing density would be carried out to determine the survey site size to use in constructing hypothetical development scenarios (such an investigation was beyond the scope of the present work). The mean number of dwellings in the Urban and Urban Neighbor housing categories (used to determine scenario size, see above) would be proportional to survey site size. If the mean housing density of Exurban survey sites were fixed at a common value for all taxa, differing survey site sizes would result in hypothetical development scenarios being created at spatial scales relevant to each taxon.

The results presented here have important implications for land use planning in areas experiencing high rates of low-density residential development. At the regional scale, a network of compact developments can result in greenways or large tracts of continuous forest habitat (Arendt 2004). Rather than building outwards from urban centers at low density to accommodate human population growth, as is now the case, we foresee outlying nodal housing developments linked with each other and the urban center by roads and surrounded primarily by forested or other natural habitat. A similar approach to planning is already being considered by some communities (e.g., 
Ingram 2005). Although the roads linking nodal developments would likely have adverse impacts on the biodiversity in greenways, the road density for nodal development would be lower than for typical dispersed housing. Finally, the location of nodal developments would have to be chosen with care to avoid the destruction or alteration of sensitive or rare habitats. For example, although clustering development limits habitat loss in Wisconsin, most clustered developments occur on lakeshores, likely negatively affecting the many sensitive species that rely on these habitats (Gonzalez-Abraham et al. 2007).

\section{CONCLUSION}

We quantified the impacts to carabid beetles of accommodating a given human population in hypothetical landscapes containing housing at different densities. We did so by sampling carabid beetle populations in forested and developed sites representing a gradient in housing density and then using these samples to estimate carabid beetle abundance and species richness in hypothetical scenarios representing the housing density/sprawl area trade-off. Our results suggest that building at a high density over a small area, rather than at a low density over a large area, minimizes the impacts of a given human population on carabid beetles.

These results have important implications for land use planning in urban areas. We suggest that nodal development, rather than typical dispersed development, be implemented in city fringes, particularly in those areas that are dominated by natural land covers, to minimize the impacts of future development on biodiversity. Considering the global scale of urbanization, future work should focus on determining the generality of the conclusions reached here by investigating the responses of forest taxa other than breeding birds and carabid beetles to the housing density/sprawl area trade-off in a variety of biomes.

Responses to this article can be read online at: http://www.ecologyandsociety.org/vol15/iss4/art12/ responses/

\section{Acknowledgments:}

This research was supported by a Natural Sciences and Engineering Research Council of Canada (NSERC) scholarship to S.A.G., and NSERC and Canada Foundation for Innovation grants to L.F. We acknowledge the generous support of private landowners, without whom this study would not have been possible. We also thank Scott Findlay, Pierre Mineau, Raphaël Proulx, and Lucas Robertson for their input and ideas. Special thanks go to Dr. Henri Goulet of Agriculture and Agri-Food Canada for his guidance in the sampling and identification of carabid beetle species.

\section{LITERATURE CITED}

Andreone, F., S. De Michelis, and V. Clima. 1999. A montane amphibian and its feeding habits: Salamandra lanzai (Caudata, Salamandridae) in the Alps of northwestern Italy. Italian Journal of Zoology 66:45-49.

Arendt, R. 2004. Linked landscapes: creating greenway corridors through conservation subdivision design strategies in the northeastern and central United States. Landscape and Urban Planning 68:241-269.

Arlettaz, R., M. Ruedi, and J. Hausser. 1993. Trophic ecology of two sibling and sympatric species of bats-Myotis myotis and Myotis blythii (Chiroptera, Vespertilionidae): first results. Mammalia 57:519-531.

Baars, M. A. 1979. Catches in pitfall traps in relation to mean densities of carabid beetles. Oecologia 41:25-46.

Blair, R. B. 1999. Birds and butterflies along an urban gradient: surrogate taxa for assessing biodiversity? Ecological Applications 9:164-170.

Bousquet, Y., and A. Larochelle. 1993. Catalogue of the Geadephaga (Coleoptera: Trachypachidae, Rhysodidae, Carabidae including Cicindelini) of America north of Mexico. Memoirs of the Entomological Society of Canada 167:1-397. 
Cavia, R., G. R. Cueto, and O. V. Suárez. 2009. Changes in rodent communities according to the landscape structure in an urban ecosystem. Landscape and Urban Planning 90:11-19.

Colwell, R. K., and J. A. Coddington. 1994. Estimating terrestrial biodiversity through extrapolation. Philosophical Transactions of the Royal Society of London, Series B: Biological Sciences 345:101-118.

Elek, Z., and G. L. Lövei. 2007. Patterns in ground beetle (Coleoptera: Carabidae) assemblages along an urbanisation gradient in Denmark. Acta Oecologica 32:104-111.

Friesen, L. E., P. F. J. Eagles, and R. J. MacKay. 1995. Effects of residential development on forestdwelling Neotropical migrant songbirds. Conservation Biology 9:1408-1414.

Gagné, S. A., and L. Fahrig. In press. The tradeoff between housing density and sprawl area: minimising impacts to forest breeding birds. Basic and Applied Ecology, doi:10.1016/j.baae.2010.09.001.

Gaublomme, E., F. Hendrickx, H. Dhuyvetter, and K. Desender. 2008. The effects of forest patch size and matrix type on changes in carabid beetle assemblages in an urbanized landscape. Biological Conservation 141:2585-2596.

Gillham, O. 2002. The limitless city: a primer on the urban sprawl debate. Island Press, Washington, D.C., USA.

Gonzalez-Abraham, C. E., V. C. Radeloff, T. J. Hawbaker, R. B. Hammer, S. I. Stewart, and M. K. Clayton. 2007. Patterns of houses and habitat loss from 1937 to 1999 in northern Wisconsin, USA. Ecological Applications 17:2011-2023.

Hansen, A. J., R. L. Knight, J. M. Marzluff, S. Powell, K. Brown, P. H. Gude, and K. Jones. 2005. Effects of exurban development on biodiversity: patterns, mechanisms, and research needs. Ecological Applications 15:1893-1905.

Hódar, J. A., F. Campos, and B. A. Rosales. 1996. Trophic ecology of the ocellated lizard Lacerta lepida in an arid zone of southern Spain: relationships with availability and daily activity of prey. Journal of Arid Environments 33:95-107.
Holland, J. M., M. A. S. Hutchison, B. Smith, and N. J. Aebischer. 2006. A review of invertebrates and seed-bearing plants as food for farmland birds in Europe. Annals of Applied Biology 148:49-71.

Holling, C. S. 1992. Cross-scale morphology, geometry, and dynamics of ecosystems. Ecological Monographs 62:447-502.

Ingram, J. 2005. Nodal development: creating compact, complete, mixed-use communities. Regional District of Nanaimo, Nanaimo, British Columbia, Canada.

Isono, M. 2005. Three approaches for cost-effective sampling of carabid beetles. Japanese Journal of Entomology 8:1-13.

Johnson, D. H. 2008. In defense of indices: the case of bird surveys. The Journal of Wildlife Management 72:857-868.

Kleppel, G.S., S. A. Madewell, and S. E. Hazzard. 2004. Responses of emergent marsh wetlands in Upstate New York to variations in urban typology. Ecology and Society 9(5):1. [online] URL: http://w ww.ecologyandsociety.org/vol9/iss5/art1/.

Kluza, D. A., C. R. Griffin, and R. M. DeGraaf. 2000. Housing developments in rural New England: effects on forest birds. Animal Conservation 3:15-26.

Lemieux, J. P., and B. S. Lindgren. 1999. A pitfall trap for large-scale trapping of Carabidae: comparison against conventional design, using two different preservatives. Pedobiologia 43:245-253.

Lenth, B. A., R. L. Knight, and W. C. Gilgert. 2006. Conservation value of compact housing developments. Conservation Biology 20:1445-1456.

Levesque, C., and G.-Y. Levesque. 1986. Activité et succession saisonnière de coléoptères épigés d'une forêt décidue du sud du Québec. Le Naturaliste Canadien 113:39-46.

Lindroth, C. H. 1961-1969. The ground beetles of Canada and Alaska. Opuscula Entomologica 1-1192. 
Maestas, J. D., R. L. Knight, and W. C. Gilgert. 2003. Biodiversity across a rural land-use gradient. Conservation Biology 17:1425-1434.

Magura, T., G. L. Lövei, and B. Tóthmérész. 2008. Time-consistent rearrangement of carabid beetle assemblages by an urbanisation gradient in Hungary. Acta Oecologica 34:233-243.

Marzluff, J. M. 2001. A historical perspective on urban bird research: trends, terms, and approaches. Pages 19-47 in J. M. Marzluff, R. Bowman, and R. Donnelly, editors. Avian ecology and conservation in an urbanizing world. Kluwer Academic Publishers, Norwell, Massachusetts, USA.

McKinney, M. L. 2002. Urbanization, biodiversity, and conservation. BioScience 52:883-890.

Odell, E. A., and R. L. Knight. 2001. Songbird and medium-sized mammal communities associated with exurban development in Pitkin County, Colorado. Conservation Biology 15:1143-1150.

Pillsbury, F. C., and J. R. Miller. 2008. Habitat and landscape characteristics underlying anuran community structure along an urban-rural gradient. Ecological Applications 18:1107-1118.

R Development Core Team. 2008. $R$ : a language and environment for statistical computing. Version 2.6.2. R Foundation for Statistical Computing, Vienna, Austria.

Sadler, J. P., E. C. Small, H. Fiszpan, M. G. Telfer, and J. Niemelä. 2006. Investigating environmental variation and landscape characteristics of an urbanrural gradient using woodland carabid assemblages. Journal of Biogeography 33:1126-1138.

Sutherland, W. J., W. M. Adams, R. B. Aronson, R. Aveling, T. M. Blackburn, S. Broad, G. Ceballos, I. M. Côté, R. M. Cowling, G. A. B. da Fonseca, E. Dinerstein, P. J. Ferraro, E. Fleishman, C. Gascon, M. Hunter, Jr., J. Hutton, P. Kareiva, A. Kuria, D. W. Macdonald, K. MacKinnon, F. J. Madgwick, M. B. Mascia, J. McNeely, E. J. Milner-Gulland, S. Moon, C. G. Morley, S. Nelson, D. Osborn, M. Pai, E. C. M. Parsons, L. S. Peck, H. Possingham, S. V. Prior, A. S. Pullin, M. R. W. Rands, J. Ranganathan, K. H. Redford, J. P. Rodriguez, F. Seymour, J. Sobel, N. S. Sodhi, A. Stott, K. Vance-Borland, and A. R. Watkinson. 2009. One hundred questions of importance to the conservation of global biological diversity. Conservation Biology 23:557-567.

Theobald, D. M. 2001. Land-use dynamics beyond the American urban fringe. The Geographical Review 91:544-564.

Work, T. T., C. M. Buddle, L. M. Korinus, and J. R. Spence. 2002. Pitfall trap size and capture of three taxa of litter-dwelling arthropods: implications for biodiversity studies. Environmental Entomology 31:438-448. 
Appendix 1. Carabid beetle abundances in survey sites and stations.

Please click here to download file 'appendix1.xls'. 
Appendix 2. Carabid beetle species collected during pitfall trapping and their estimated abundances in development scenarios. We classified beetles as 'native', 'non-native', 'forest' and 'open-habitat' species according to Lindroth (1961-1969). We defined forest species as those that occur primarily in forested or wooded habitat, and in some cases open country. We defined open-habitat species as those occurring in a variety of openhabitat types (e.g., open woods, meadows, fields) including roadsides, gravel pits and cultivated ground. If the habitat affinity of a species was not recorded in Lindroth (19611969), we classified the species according to H. Goulet (Agriculture and Agri-Food Canada, personal communication) with two exceptions. The habitat affinity of Cicindela sexguttata was determined according to Schultz (1998) and the habitat affinity of Trichotichnus vulpeculus was determined according to Stanton et al. (2003) and Webster and Bousquet (2008).

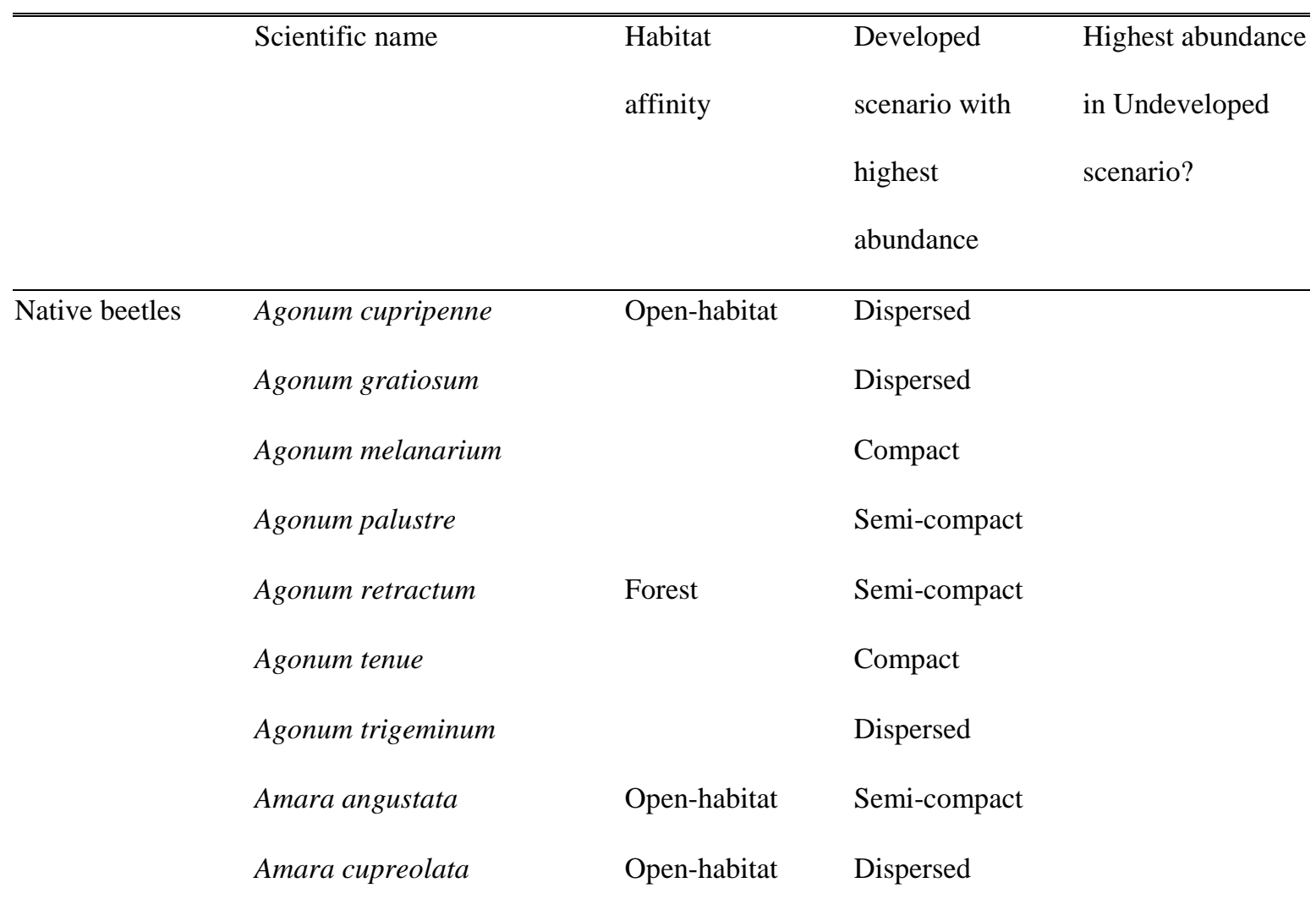




\begin{tabular}{|c|c|c|}
\hline Amara impuncticollis & Open-habitat & Semi-compact \\
\hline Amara patruelis & Open-habitat & Semi-compact \\
\hline Amara rubrica & Open-habitat & Compact \\
\hline Amphasia interstitialis & Forest & Semi-compact \\
\hline Anisodactylus harrisii & Open-habitat & Dispersed \\
\hline Anisodactylus kirbyi & & Compact \\
\hline Anisodactylus merula & Open-habitat & Compact \\
\hline Anisodactylus rusticus & Open-habitat & Semi-compact \\
\hline Anisodactylus verticalis & Forest & Compact \\
\hline Badister notatus & & Dispersed \\
\hline Badister ocularis & & Dispersed \\
\hline Bembidion frontale & & Compact \\
\hline Bembidion inaequale & & Semi-compact \\
\hline Bembidion praticola & Forest & Compact \\
\hline Bembidion quadrimaculatum & Open-habitat & Dispersed \\
\hline oppositum & & \\
\hline Bembidion variegatum & & Compact \\
\hline Bembidion versicolor & & Dispersed \\
\hline Brachinus medius & & Compact \\
\hline Bradycellus lugubris & Open-habitat & Compact \\
\hline Calathus gregarius & Forest & Dispersed \\
\hline Carabus maeander & Open-habitat & Dispersed \\
\hline Chlaenius emarginatus & Forest & Dispersed \\
\hline Chlaenius impunctifrons & & Compact \\
\hline Chlaenius lithophilus & & Semi-compact \\
\hline Chlaenius niger & & Dispersed \\
\hline Chlaenius tricolor & Open-habitat & Dispersed \\
\hline
\end{tabular}




\begin{tabular}{|c|c|c|}
\hline Cicindela sexguttata & Forest & Dispersed \\
\hline Cymindis cribricollis & Forest & Compact \\
\hline Cymindis neglectus & Forest & Compact \\
\hline Diplocheila obtusa & Open-habitat & Dispersed \\
\hline Dyschirius globulosus & & Dispersed \\
\hline Elaphropus granarius & Open-habitat & Compact \\
\hline Elaphrus clairvillei & Forest & Dispersed \\
\hline Harpalus compar & Open-habitat & Semi-compact \\
\hline Harpalus eraticus & Open-habitat & Semi-compact \\
\hline Harpalus erythropus & Open-habitat & Semi-compact \\
\hline Harpalus faunus & Open-habitat & Semi-compact \\
\hline Harpalus fulvilabris & Forest & Compact \\
\hline Harpalus herbivagus & Open-habitat & Dispersed \\
\hline Harpalus longicollis & Open-habitat & Semi-compact \\
\hline Harpalus opacipennis & Open-habitat & Semi-compact \\
\hline Harpalus pensylvanicus & Open-habitat & Semi-compact \\
\hline Harpalus providens & Forest & Dispersed \\
\hline Harpalus somnulentus & Open-habitat & Dispersed \\
\hline Lophoglossus scrutator & & Compact \\
\hline Loricera pilicornis & & Compact \\
\hline Loxandrus commutabilis & Open-habitat & Dispersed \\
\hline Myas cyanescens & Forest & Compact \\
\hline Notiophilus aeneus & Forest & Compact \\
\hline Olisthopus micans & Forest & Compact \\
\hline Olisthopus parmatus & Forest & Dispersed \\
\hline Oxypselaphus pusillus & Open-habitat & Compact \\
\hline Patrobus longicornis & Open-habitat & Compact \\
\hline
\end{tabular}




\begin{tabular}{|c|c|c|c|c|}
\hline & Platynus decentis & Forest & Dispersed & \\
\hline & Poecilus lucublandus & Open-habitat & Compact & \\
\hline & lucublandus & & & \\
\hline & Pseudamara arenaria & Forest & Compact & Yes \\
\hline & Pterostichus caudicalis & & Compact & \\
\hline & Pterostichus coracinus & Forest & Compact & Yes \\
\hline & Pterostichus corvinus & & Dispersed & \\
\hline & Pterostichus luctuosus & & Dispersed & \\
\hline & Pterostichus mutus & Open-habitat & Semi-compact & \\
\hline & Pterostichus patruelis & & Dispersed & \\
\hline & Pterostichus pensylvanicus & Forest & Dispersed & \\
\hline & Pterostichus tristis & Forest & Compact & \\
\hline & Sphaeroderus canadensis & Forest & Compact & Yes \\
\hline & canadensis & & & \\
\hline & Sphaeroderus stenostomus & Forest & Compact & \\
\hline & lecontei & & & \\
\hline & Stenolophus conjunctus & Open-habitat & Semi-compact & \\
\hline & Syntomus americanus & Open-habitat & Dispersed & \\
\hline & Synuchus impunctatus & Forest & Compact & Yes \\
\hline & Trechus apicalis & Forest & Compact & Yes \\
\hline & Trichotichnus vulpeculus & Forest & Semi-compact & \\
\hline Non-native beetles & Agonum muelleri & Open-habitat & Semi-compact & \\
\hline & Amara aenea & Open-habitat & Dispersed & \\
\hline & Amara apricaria & Open-habitat & Compact & \\
\hline & Bembidion obtusum & Open-habitat & Compact & \\
\hline & Bembidion tetracolum & Open-habitat & Semi-compact & \\
\hline & Carabus granulatus & Open-habitat & Semi-compact & \\
\hline
\end{tabular}




$\begin{array}{lll}\text { Carabus nemoralis } & \text { Open-habitat } & \text { Dispersed } \\ \text { Clivina fossor } & \text { Open-habitat } & \text { Compact } \\ \text { Harpalus affinis } & \text { Open-habitat } & \text { Compact } \\ \text { Pterostichus melanarius } & \text { Open-habitat } & \text { Dispersed }\end{array}$

\section{LITERATURE CITED}

Lindroth, C. H. 1961-1969. The ground beetles of Canada and Alaska. Opuscula Entomologica 1-1192.

Schultz, T. D. 1998. The utilization of patchy thermal microhabitats by the ectothermic insect predator, Cicindela sexguttata. Ecological Entomology 23:444-450.

Stanton, R. C., D. J. Horn, F. F. Purrington, J. W. Peacock, and E. H. Metzler. 2003. Monitoring selected arthropods. Pages 123-138 in E. Kennedy Sutherland, and T. F. Hutchinson, editors. Characteristics of mixed-oak forest ecosystems in southern Ohio prior to the reintroduction of fire. General Technical Report NE-299. United States Department of Agriculture Forest Service, Newtown Square, Pennsylvania, USA.

Webster, R. P., and Y. Bousquet. 2008. New ground beetle (Coleoptera: Carabidae) records in New Brunswick, Canada. Journal of the Acadian Entomological Society 4:1424. 